\title{
Prevalence and risks factors of overweight/obesity among Under- graduate students: An institutional based cross-sectional study, Ghana
}

\author{
C. Obirikorang ${ }^{1}$, E.O. Anto ${ }^{1,4}$, P. Addai ${ }^{2}$, Y. Obirikorang 3 and E. Acheampong ${ }^{1}$ \\ ${ }^{1}$ Department of Molecular Medicine, School of Medical Science, ${ }^{2}$ Department of Medical Laboratory Technology, Faculty of Allied Health \\ Sciences, Kwame Nkrumah University of Science and Technology, ${ }^{3}$ Department of Nursing, Garden City University College, Kenyasi, \\ Kumasi, Ghana, ${ }^{4}$ School of Medical and Health Science, Edith Cowan University, Joondalup, Australia
}

\begin{abstract}
Obesity and overweight are lifestyle conditions affecting more than half of the younger adult population. This study determined the prevalence and risks factors of obesity and overweight among undergraduate students in Kwame Nkrumah University of Science and Technology, Kumasi, Ghana. This institutional based cross-sectional study conducted between November, 2013 and February, 2014 recruited three hundred (300) students from the various academic colleges. Self-structured questionnaire was used to obtain socio-demographic and lifestyle related characteristics. Blood pressure, weight, height, waist circumference (WC) and hip circumference (HC) were measured. The overall prevalence of obesity and overweight was $1.7 \%(5 / 300)$ and $16.0 \%$ (48/300) using BMI; 13.3\% (40/300) and 8.7\% (26/300) using WC; $19.0 \%$ $(57 / 300)$ and $20.0 \%(60 / 300)$ respectively using WHR while obesity was $28.7 \%(86 / 300)$ using WHtR. Generally, obesity was higher in females than males $(\mathrm{p}=0.0149)$. Drinking $2-4$ bottle of alcohol per day was associated with obesity than overweight $(40.0 \%(2 / 5)$ vs. $8.3 \%(4 / 48) ; \mathrm{p}=0.0175)$. Increased prevalence of obesity was associated with fourth year students. About $22.9 \%(11 / 48)$ of students in Agric and natural science were more likely to be overweight while $40.0 \%(2 / 5)$ from health sciences were more likely to be obese. Akans and Ga-Adangbes' were more likely to be overweight and obese respectively. Being female was an independent risk factor for obesity/overweight $(\mathrm{OR}=12.67,95 \% \mathrm{CI}=0.926-17.042 ; \mathrm{p}=0.0020)$. This study indicated that obesity and overweight were predominantly associated with female undergraduate students. The use of WC, WHR and WHtR in combination with BMI is essential.

Journal of Medical and Biomedical Sciences (2017) 6(1), 24-34
\end{abstract}

Keywords: Obesity, Overweight, Risk, undergraduate, students

\section{INTRODUCTION}

Globally, over 300 million and 1.1 billion cases of adult obesity and overweight respectively are reported annually (WHO, 2000). The trend of obesity tends to peak since 1960's predisposing individuals to hypertension, diabetes, and other cardiovascularrelated morbidities and mortalities (Sturm, 2002). Obesity does not only occur in older adult population, but also in children, teenagers and young adults (Gopalakrishnan et al., 2012). Several studies have indicated that increased prevalence of obesity in sub-

Correspondence: Christian Obirikorang, Dept. of Molecular Medicine, Kwame Nkrumah University of Science and Technology, Kumasi, Ghana

E-mail:krisobiri@yahoo.com
Saharan African countries is common among women (Kruger et al., 2005; Mogre et al., 2012).

There is convincing evidence that obesity play a role in the development of insulin resistance and metabolic syndrome (McKeigue et al., 1991). A number of factors such as physical inactivity combined with high-calorie intake, smoking, alcohol intake, low-cost foods have been implicated in obesity and overweight (Gupta et al., 2009). Academic stress also plays an important role leading to irregularities in diet and hence obesity.

Increased prevalence of obesity among undergraduate students has been extensively explored by several authors (Beatrice Adderley-Kelly PhD, 2007; Gopalakrishnan et al., 2012; Mogre et al., 2014). How- 


\section{Obesity prevalence among undergraduates}

Obirikorang et al.,

ever, these pattern are inconsistent due to ethnicity and culture difference and more importantly environment and lifestyle changes emanating from economic development, modernization, and urbanization.

The routine use of BMI to determine obesity has not proven to be sufficient though other anthropometric measurements like WC, waist-to-hip ratio (WHR) and waist-to-height (WHtR) are underutilized. There is paucity of data on institutional based prevalence of obesity and overweight across the globe. No study in the southern part of Ghana has so far considered the prevalence in the various academic levels and colleges as well as ethnic origin of these students. The need to create earliest awareness of obesity associated risk factors among students would go a long way to curb future obesity and related medical conditions including diabetes and hypertension. Therefore, this study determined the prevalence of overweight and obesity and associated risk factors among undergraduate students in Kwame Nkrumah University of Science and Technology, Ghana.

\section{MATERIALS AND METHODS}

\section{Study design/settings}

This institutional based cross-sectional descriptive study took place at Kwame Nkrumah University of Science and Technology (KNUST), Ghana between the periods of November, 2013 and February, 2014. KNUST is a public university located in Kumasi in the Ashanti Region of Ghana. The main university campus which is about seven square miles in area is situated about eight $(8)$ miles $(13 \mathrm{~km})$ to the east of Kumasi. There are six halls of residence at the main campus. The university has about 40000 undergraduate students and it consists of six (6) colleges and thirty departments.

\section{Ethical consideration}

Ethical approval was sought for and granted by the Committee on Human Research, Publications and Ethics (CHRPE), Kwame Nkrumah University of Science \& Technology (KNUST). Participants were then informed about their rights to not participate in the study and verbal consent was taken before they answered the questionnaire. Confidentiality of par- ticipants' information given was preserved.

\section{Study population/Subjects selection}

A clustered randomized sampling technique was used to recruit three hundred (300) undergraduate students (122 (first year), 65 (second year), 58 (third year) and 55 (fourth year) for this study. Sample size was calculated using distribution response rate of $50 \%$, with the $95 \%$ confidence interval (CI), significance level 0.05 and power of the study is $80 \%$. Thus the minimum size required was 300 .

\section{Data collection}

A self-structured questionnaire was designed by reviewing relevant literatures and questionnaires previously used in similar studies. The study questionnaire was first pre-tested and suitable modifications were made. Information such as sociodemographic characteristics, physical activity, alcohol intake, sedentary activities, smoking and family history of hypertension were obtained using a structured questionnaire. Students aged between 18-31 years who have registered and are undertaking courses from various colleges (Agric \& Natural Science, Architecture and Planning, Engineering, Art and Social Science, Health Sciences and Sciences) were included for this study. Students who did not consent for the study were excluded.

\section{Blood pressure and Anthropometric measure- ments}

Blood pressure was measured by a trained Nurse with the participants -remaining seated for 10 minutes using an automated BP monitor (Omron HEM711DLX, UK) at the student clinic facilities. Weight of the students was measured in the upright position to the nearest $0.5 \mathrm{~kg}$ using a weight measuring scale (Seca, Hamburg, Deutschland). Height was measured without shoes to the nearest $0.1 \mathrm{~m}$ using a well calibrated wall mounted rule. BMI was calculated based on weight in kilograms divided by the square of the height in metres $\left(\mathrm{kg} / \mathrm{m}^{2}\right)$. Waist circumference (WC) was measured to the nearest $0.1 \mathrm{~cm}$ horizontally at the narrowest point between lower end of the rib cage and iliac crest. Hip circumference was measured to the nearest $0.1 \mathrm{~cm}$ at the greatest horizontal circumference below the 


\section{Obesity prevalence among undergraduates}

Obirikorang et al.,

iliac crest at the level of greater trochanter (the widest portion on the buttocks). Waist and hip circumference were measured with an inelastic tape measure. Waist-to-hip ratio (WHR) and waist-to-height (WHtR) ratios were calculated.

Definition of anthropometric terms and academic levels

BMI were classified based on WHO definition for adults as underweight $\left(<18.5 \mathrm{~kg} / \mathrm{m}^{2}\right)$, normal $(18.5-$ $\left.24.9 \mathrm{~kg} / \mathrm{m}^{2}\right)$, overweight $\left(25-29.9 \mathrm{~kg} / \mathrm{m}^{2}\right)$ and obese $\left(>30 \mathrm{~kg} / \mathrm{m}^{2}\right)$ (Status, 1995). Level 100 represented first year undergraduate students while 200, 300 and 400 characterized second, third and fourth year students respectively. Male students with a waist circumference of $<94,94-101.9$ and $\geq 102 \mathrm{~cm}$ were classified as normal weight, overweight and obese respectively, while female were classified in the same obesity categories on the basis of WC $<80,80-87.9$ and $\geq 88 \mathrm{~cm}$. Male students with WHR $<0.90,0.90$ -0.99 and $\geq 1.0$ were classified as normal weight, overweight or obese respectively, while female students were classified in the same categories on the basis of WHR of $<0.80,0.80-0.84$ and $\geq 0.85$ (Croft et al., 1995; WHO, 2000). Concerning WHtR the cut-off value of $\geq 0.5$ indicates obesity (Ashwell, 2009).

\section{Statistical analysis}

Data were entered into Microsoft Excel 2010 and statistical analyses performed using GraphPad Prism 6.0 (Graph Pad software, San Diego California USA, www.graphpad.com). Categorical variables are presented in frequency (proportion) and test of association between proportions was done using Chisquare. Multiple logistic regression was employed to determine the associated risk factors of overweight/ obesity. Unpaired sample t-test was used to compare between two means of continuous variables, which were expressed as means \pm Standard error of mean (SEM). $\mathrm{p}<0.05$ was considered as statistically significant level.

\section{RESULTS}

Socio-demographic characteristics of study participant are shown in table 1 . Majority of the participants were males 59.7\% (179/300). Participants within the age range of 19-24years were the most represented group while only 1.0\% (3/300) of them were 30 years and above. Exactly 97.3\% (292/300) of them were single, while $2.3 \%(7 / 300)$ and $0.3 \%$ $(1 / 300)$ were married and cohabiting respectively. Most of the participants $40.7 \%(122 / 300)$ were in first year followed $21.7 \%(65 / 300)$ in second year, third year 19.3\% (58/300) and fourth year 18.3\% (55/300). Higher proportions $22.7 \%(68 / 300)$ of the participants were from the College of Art and Social Science, Engineering 18.0\% (54/300), Health Science $17.7 \%$ (53/300), Agric and Natural sciences 15.7\% (47/300), Sciences 14.0\% (42/300) and Architecture and Planning 12.0\% (36/300) respectively (Table 1).

Table 2 shows mean blood pressure and anthropometric measurement of study participants in relation to gender. The mean age of participants was $20.88 \pm 0.80$ years. Males $(21.25 \pm 0.6$ years $)$ were older than female $(20.35 \pm 0.3$ years $)(p=0.002)$. However, no statistical significance difference was observed in mean SBP $\quad(115.4 \pm 1.5$ vs. $114.5 \pm 1.1 \mathrm{mmHg}$; $\mathrm{p}=0.248)$ and DBP $(70.6 \pm 0.3$ vs. $71.0 \pm 0.4 \mathrm{mmHg}$; $\mathrm{p}=0.654)$ of male compared to females. Females had increased BMI $\left(22.78 \pm 0.3 \mathrm{~kg} / \mathrm{m}^{2}\right)$ compared to male $\left(21.28 \pm 0.2 \mathrm{~kg} / \mathrm{m}^{2}\right)(\mathrm{p}<0.0001)$. A significantly increased waist/hip ratio $(\mathrm{p}=0.033)$ and waist/height ratio $(p<0.0001)$ were observed among female compared to male. Conversely, the mean waist circumference of females did not significantly differ from their male counter (Table 2).

Table 3 depicts demographic and lifestyle related characteristics stratified in order of BMI severity. Obesity was prevalent among aged group 19-24 years $60.0 \%(3 / 5)$ compared to the other age groups. Age was not significantly associated with BMI (<18years $(\mathrm{p}=0.7924)$; 19-24years $(\mathrm{p}=0.8207)$; 25-30years $(p=0.7679)$; $\geq 31$ year $(p=0.5890))$. Females $80.0 \%$ (4/5) were more obese than male $20.0 \%(1 / 5) \quad(\mathrm{p}=0.0149)$. Drinking $2-4$ bottle of alcohol per day was associated with obesity than overweight $\quad(40.0 \% \quad(2 / 5) \quad$ vs. $8.3 \% \quad(4 / 48)$; $\mathrm{p}=0.0175)$. However, smoking $(\mathrm{p}=0.893)$, physical activities $(p=0.2829)$, fast food intake $(p=0.500)$, family history of HTN $(p=0.3209)$ and sleep imme- 
Obesity prevalence among undergraduates

Obirikorang et al.,

Table 1-Sociodemographic characteristics of study population stratified by gender

\begin{tabular}{lcccc}
\hline Variable & Total, $\mathrm{n}(\%)$ & Males, $\mathrm{n}(\%)$ & Females, $\mathrm{n}(\%)$ & $\mathrm{p}$-value \\
\hline Age range (year) & & & & \\
$<18$ & $50(16.7)$ & $22(12.3)$ & $28(23.1)$ & 0.0175 \\
$19-24$ & $229(76.3)$ & $142(79.3)$ & $87(79.9)$ & 0.1661 \\
$25-30$ & $18(6.0)$ & $13(7.3)$ & $5(4.1)$ & 0.3268 \\
$\geq 31$ & $3(1.0)$ & $2(1.1)$ & $1(0.8)$ & 1.0000 \\
Marital status & & & & \\
single & $292(97.3)$ & $174(97.2)$ & $118(97.5)$ & 1.0000 \\
married & $7(2.3)$ & $5(2.8)$ & $2(1.7)$ & 0.7055 \\
Cohabiting & $1(0.3)$ & $0(0.0)$ & $1(0.8)$ & 0.4033 \\
Academic year & & & & \\
First year & $122(40.7)$ & $72(40.2)$ & $50(41.3)$ & 0.9048 \\
Second year & $65(21.7)$ & $32(17.9)$ & $33(27.3)$ & 0.0633 \\
Third year & $58(19.3)$ & $36(20.1)$ & $22(18.2)$ & 0.7662 \\
Fourth year & $55(18.3)$ & $39(21.8)$ & $16(13.2)$ & 0.6851 \\
College & & & & \\
ANS & $47(15.7)$ & $28(15.6)$ & $19(15.7)$ & 1.0000 \\
AP & $36(12.0)$ & $15(8.4)$ & $21(17.4)$ & 0.0286 \\
EG & $54(18.0)$ & $42(23.5)$ & $12(9.9)$ & 0.0033 \\
ASS & $68(22.7)$ & $37(20.7)$ & $31(25.6)$ & 0.3281 \\
HS & $53(17.6)$ & $26(14.5)$ & $27(22.3)$ & 0.0911 \\
S & $42(14.0)$ & $31(17.3)$ & $11(9.1)$ & 0.0611 \\
Ethnicity & & & & \\
Akan & $134(44.7)$ & $90(50.3)$ & $44(36.4)$ & 0.0184 \\
Ga-Adangbe & $54(18.0)$ & $29(16.2)$ & $25(20.7)$ & 0.3594 \\
Ewe & $45(15.0)$ & $26(14.5)$ & $19(15.7)$ & 0.8693 \\
Mole-Dagbani & $60(20.0)$ & $32(17.9)$ & $28(23.1)$ & 0.3036 \\
Fante & $7(2.3)$ & $2(1.1)$ & $5(4.1)$ & 0.1225 \\
\hline
\end{tabular}

Values are presented as frequency (percentage). Comparison was done using Fischer exact test. Level of significance was p<0.05. ANS: Agric. \& Natural Science; AP: Architecture and Planning; EG: Engineering ASS: Art and Social Science; HS: Health Science; S: Sciences

Table 2: Clinical and Anthropometric measurement of study participants in relation to Gender

\begin{tabular}{lcccc}
\hline Variables & Total $(\mathrm{n}=300)$ & Males $(\mathrm{n}=179)$ & Females $(\mathrm{n}=121)$ & $\mathrm{p}$-value \\
\hline Age $(\mathrm{years})$ & $20.88 \pm 0.80$ & $21.25 \pm 0.6$ & $20.35 \pm 0.3$ & 0.002 \\
SBP $(\mathrm{mmHg})$ & $115.1 \pm 1.3$ & $115.4 \pm 1.5$ & $114.5 \pm 1.1$ & 0.248 \\
DBP $(\mathrm{mmHg})$ & $70.8 \pm 0.41$ & $70.6 \pm 0.3$ & $71.0 \pm 0.4$ & 0.654 \\
BMI $\left(\mathrm{Kg} / \mathrm{m}^{2}\right)$ & $21.85 \pm 0.32$ & $21.28 \pm 0.2$ & $22.78 \pm 0.3$ & $<0.0001$ \\
WC $(\mathrm{cm})$ & $80.21 \pm 0.59$ & $80.41 \pm 0.67$ & $80.00 \pm 0.71$ & 0.702 \\
WHR & $0.85 \pm 0.07$ & $0.83 \pm 0.07$ & $0.85 \pm 0.06$ & 0.033 \\
WHtR & $0.475 \pm 0.001$ & $0.465 \pm 0.004$ & $0.491 \pm 0.006$ & $<0.0001$ \\
\hline
\end{tabular}

Values are in Mean \pm standard error of means (SEM). $P$ value defines the level of significance when males are compared to female (unpaired t test). WC: Waist circumference; WHR: Waist/hip Ratio; WHtR: Waist to height ratio 
Obesity prevalence among undergraduates

Obirikorang et al.,

Table 3: Demographic and lifestyle related characteristics in association with BMI classifications

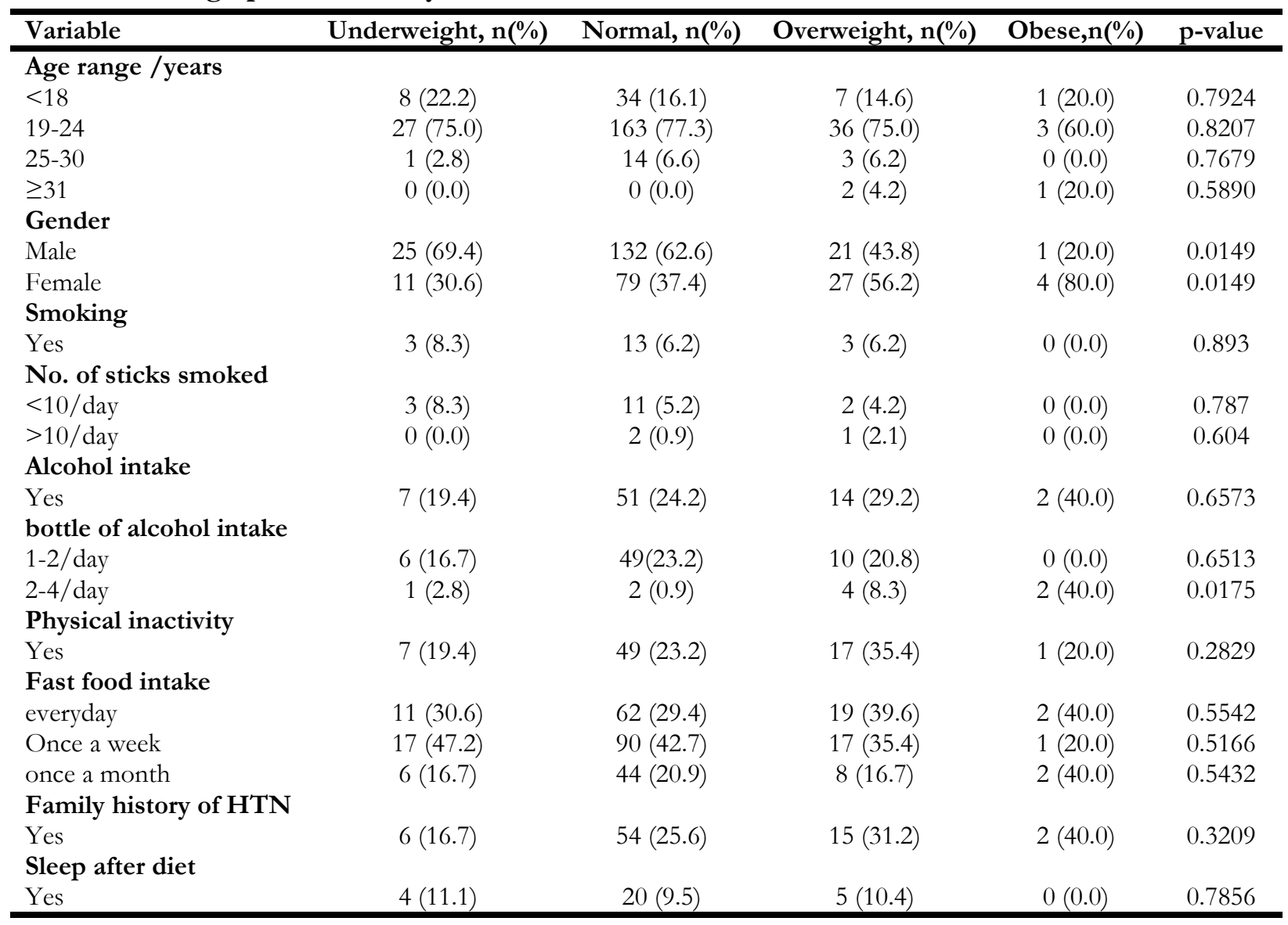

Values are presented as n (\%): frequency (percentage). Comparison was done using Fischer exact test. Level of significance was $p<0.05$. HTN: hypertension

diately after diet $(\mathrm{p}=0.7856)$ did not show any significant association with BMI ( $\mathrm{p}>0.05)$ (Table 3).

The overall prevalence of obesity in this study was $1.7 \%(5 / 300)$. High prevalence of obesity were amongst the fourth year students $1.8 \%(1 / 55)$ followed by third year $1.7 \%(1 / 58)$ and then first year $1.6 \%(2 / 122)$. However, no significance difference in prevalence of obesity proportion was observed among the academic year group ( $1{ }^{\text {st }}$ year vs $2^{\text {nd }}$ year $(p=0.988) ; 3^{\text {td }}$ year vs $4^{\text {th }}$ year $\left.(p=0.999)\right)$. Participants in second year recorded the highest proportion $21.5 \%(14 / 65)$ of overweight compared to other academic year (first year 12.3\% (15/122), third year $13.8 \%(8 / 58)$ and $20.0 \%(11 / 55)$ in fourth year) (Figure 1).
Higher proportion $22.9 \%(11 / 48)$ of students from the college of Agric and Natural science were overweight while students $40.0 \%(2 / 5)$ from the college of health sciences were more likely to be obese using BMI classification (Figure 2).

Table 4 shows an association of WC, WHR and WHtR with socio-demographic characteristics. There was a significant association between the WHR status and gender $(p<0.0001)$. WC was significantly associated with gender $(\mathrm{p}<0.0001)$, year of academia $(p<0.0001)$ and the affiliate college of study $(\mathrm{p}=0.0212)$. WHtR status was significantly associated with gender $(\mathrm{p}<0.0001)$, year of academia $(p=0.0037)$ and the affiliate college of study $(\mathrm{p}=0.0150)$. 
Obesity prevalence among undergraduates

Obirikorang et al.,
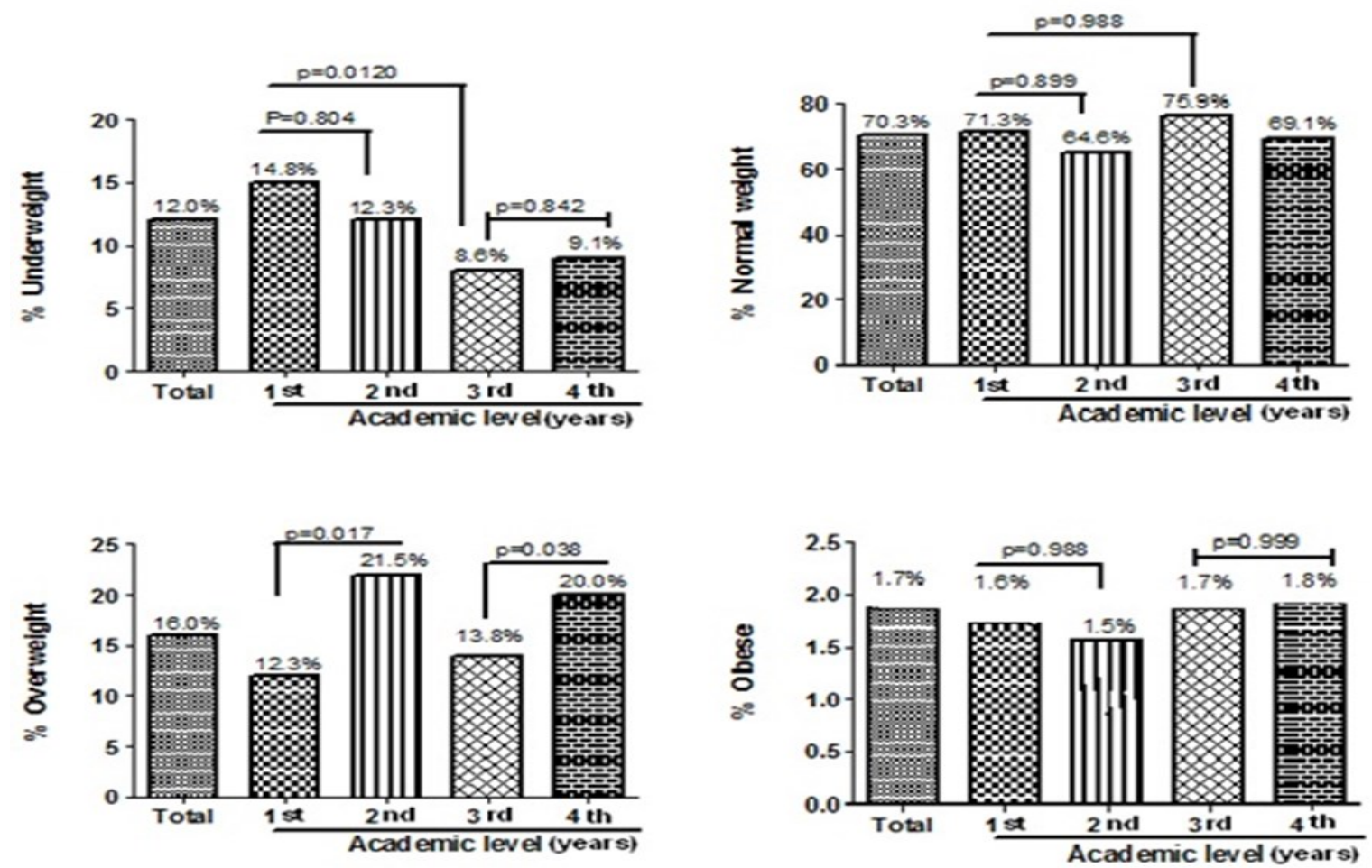

Figure 1-Prevalence and association between BMI status and student's academic level
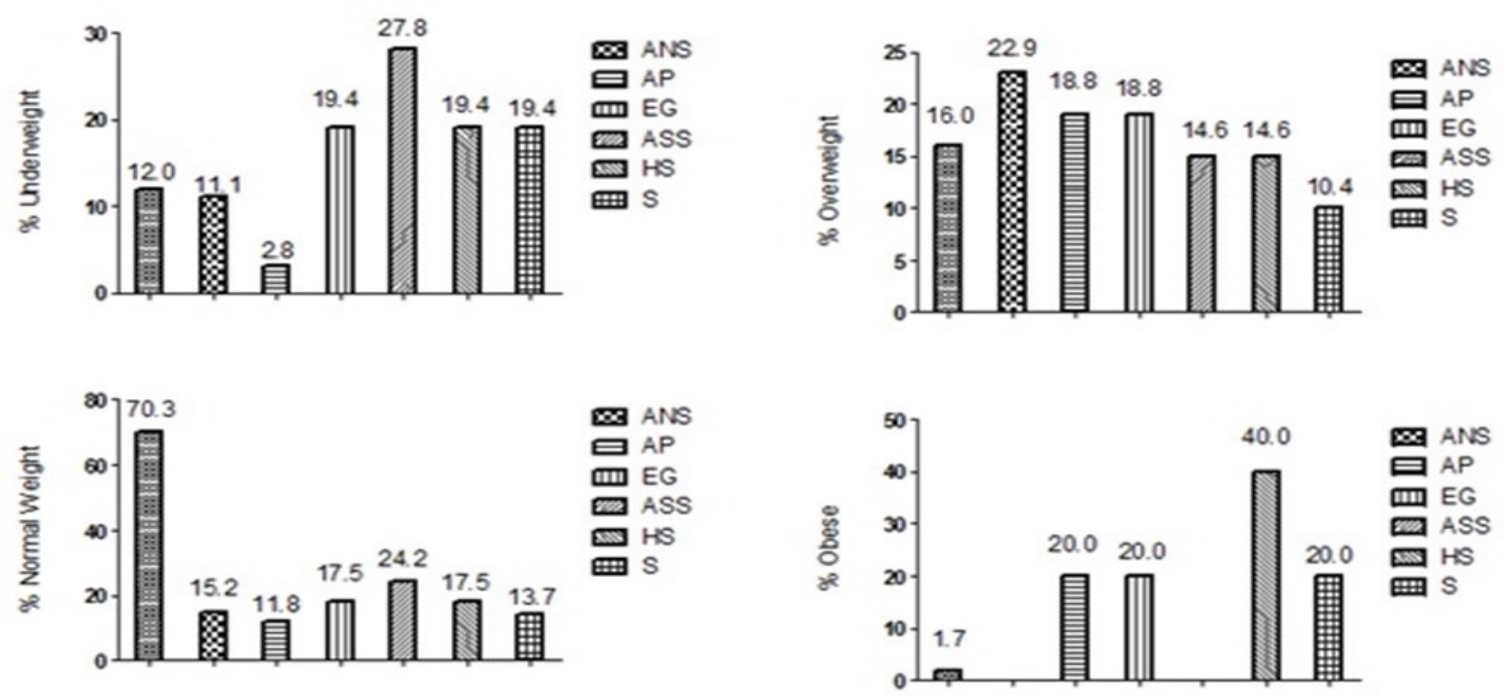

Figure 2-Prevalence of BMI in association with various colleges. Agric. \& Natural Science; AP: Architecture and Planning; EG: Engineering ASS: Art and Social Science; HS: Health Science; S: Sciences 


\section{Obesity prevalence among undergraduates}

Obirikorang et al.,

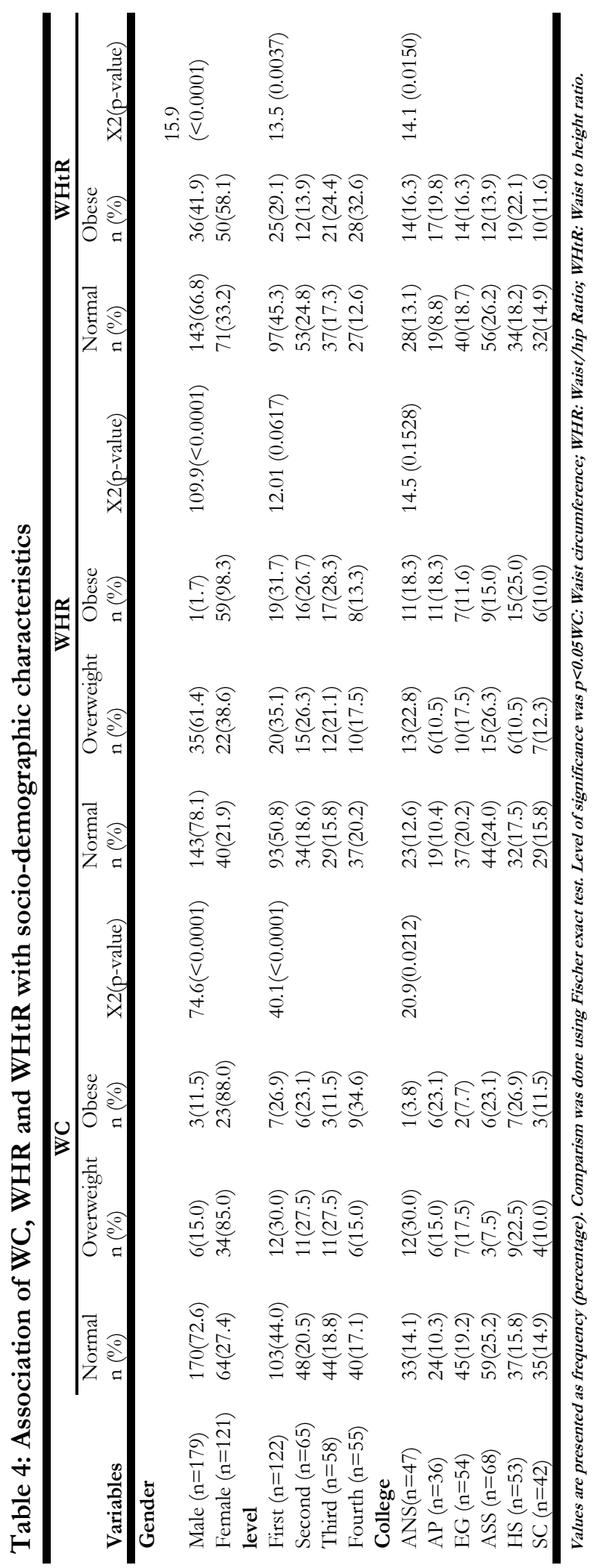

Table 5 shows the association between BMI and Ethnicity. Akan students were more likely to be overweight than being obese $(45.8 \%(22 / 48)$ vs. $20.0 \%(1 / 5))$ while students from Ga-Adangbe were more obese than overweight $(40.0 \%(2 / 5)$ vs. $20.8 \%(10 / 48))$. There was a significant association between BMI status and ethnicity $(\mathrm{p}=0.0367)$ (Table 5).

Table 6 depicts multivariate logistic regression analysis of predictor or risk factor for obesity. Risk factors of general obesity were being female $(\mathrm{OR}=$ 12.67, 95\% CI $=0.926-17.042 ; \mathrm{p}=0.0057)$. Age, smoking, alcohol intake, family history of hypertension and obesity, physical inactivity, fast food intake did not show any significant predictive ability for obesity condition (Table 6).

\section{DISCUSSION}

Obesity is a global epidemic affecting about 1.1 billion of adult population (WHO, 2000). This study assessed the prevalence and risk factors associated with overweight/obesity among undergraduate students at KNUST, Ghana and also to create public health awareness on the need to foster healthy lifestyle to prevent future risk of obesity. The overall prevalence of obesity and overweight observed in this study was $1.7 \%$ and $16.0 \%$ respectively. Similar findings have been observed in previous studies conducted by Mogre et al. (2014) in Ghana (1.9\% vs. 9.3\%), Chhabra et al. (2006) in Delhi $(2.0 \%$ vs. $11.4 \%)$ and Gopalakrishnan et al. (2012) in Malaysia (5.2\% vs. $14.8 \%$ ). The prevalence rate of overweight observed in the current study is higher compared to that observed by Morge and colleagues in the University of Development studies in the Northern part of Ghana.

The prevalence of overweight and obesity using WC, WHR and WHtR was significantly higher compared to using BMI. This is consistent with findings from previous studies that reported increased prevalence of obesity using WHR and WC (Akpinar et al., 2007; Bhurosy and Jeewon, 2013), and WHtR (Ashwell, 2009). However, other cohort study found both WC and BMI to have equal diagnostic accuracy for obesity as a component for met- 


\section{Obesity prevalence among undergraduates}

Obirikorang et al.,

Table 5-Association between BMI and Ethnicity

\begin{tabular}{lllllll}
\hline Ethnicity & Underweight, $\mathbf{n}(\%)$ & Normal, $\mathbf{n}(\%)$ & Overweight, $\mathbf{n}(\%)$ & Obese, $\mathbf{n}(\%)$ & $\mathbf{X}^{2}$ & p-value \\
\hline Akan & $16(44.4)$ & $101(47.8)$ & $22(45.8)$ & $1(20.0)$ & 4.613 & 0.0367 \\
Ga-Adangbe & $5(13.9)$ & $37(17.5)$ & $10(20.8)$ & $2(40.0)$ & & \\
Ewe & $6(16.7)$ & $30(14.2)$ & $9(18.8)$ & $1(0.0)$ & \\
Dagbani-Mole & $9(25.0)$ & $43(20.4)$ & $7(14.6)$ & $1(20.0)$ & & \\
\hline
\end{tabular}

Values are presented as frequency (percentage). Comparism was done using Chi-square test, P<0.05 was statistically significant

Table 6- Multiple logistic regression analysis to determine predictors of overweight/obesity

\begin{tabular}{lcccc}
\hline Variables & B & Adjusted OR & 95\% CI of OR & p-value \\
\hline Age & -0.252 & 0.777 & $0.601-1.005$ & 0.0550 \\
Smoking & 16.474 & 1.427 & $0.049-3.056$ & 0.9980 \\
Alcohol intake & -0.697 & 0.498 & $0.068-3.655$ & 0.4930 \\
FH HTN and Obesity & -0.613 & 0.542 & $0.075-3.929$ & 0.5440 \\
Physical inactivity & -0.151 & 0.860 & $0.731-1.012$ & 0.0700 \\
Gender (Female) & 2.538 & 12.656 & $0.926-17.042$ & 0.0020 \\
Fast food intake & -0.003 & 0.997 & $0.296-3.363$ & 0.4200 \\
\hline
\end{tabular}

FH HTN: family history of hypertension. OR: odds ratio; B: regression coefficient

abolic syndrome (Han et al., 2002). Discrepancies in results suggest that prognostic ability of each index of obesity may differ by age, gender and ethnic group. Based on this study, we found that using WHtR reported the highest prevalence of obesity $(28.7 \%)$ compared to using BMI $(1.7 \%)$.

Several authors have consistently reported that increase prevalence of overweight and obesity are associated with females in various studies (Oghagbon et al., 2009; Mogre et al., 2014; Onyechi and Okolo, 2017). Findings from this study concur with reports from earlier authors as increased prevalence of overweight and obesity was observed in female students compared to the male counterparts. The proportion of obesity in females was extremely high in this study compared to a current study by Mogre et al. (2014).

The higher rate of obesity and overweight among the female students is expected because there is a social perception in Ghana that females who are fat are considered to be living good in the society compared to those with slender body. Some contracep- tives containing progestogen may cause the body to produce increase amount of fat in the females (Reid et al., 1992) and thus might also be a contribution factor to the increment in weight among females in this study; though our present study did not purposively recruit female students on contraceptives.

Results from this study found that obesity was increasing with increasing academic level. High prevalence of obesity was observed among the fourth year $(1.8 \%)$, followed by third year $(1.7 \%)$ students. Meanwhile the highest prevalence of overweight was recorded among level 200s. The long duration spent using computer, eating more during time of stress and snacking between meals are the most important life style factors likely to contribute to increased prevalence of overweight/obesity (Bakr et al., 2001).

The prevalence of underweight using BMI classification decreased with increasing academic level up to third year (in this order $14.8 \%, 12.3 \%, 8.6 \%$ ) but transiently rises in fourth year $(9.1 \%)$. This finding support the fact that first year students undergo a 


\section{Obesity prevalence among undergraduates}

Obirikorang et al.,

lot of stress and other difficulties trying to adapt to their new environment but as the year progresses they successfully adapt to their new environment and try to take things lighter even with examination (Nakalema and Ssenyonga, 2014).

Fourth year students are confronted with two challenges i.e. passing their final exams and submitting their project work. These no doubts present them with a huge workload which may lead to their restlessness thereby causing loss in weight. The stress also explains why there was high prevalence of obesity among fourth year students (Gupta et al., 2009). Although the mechanism of cortisol a stress releasing hormone involvement in the development of obesity is not clear, several researchers have identified an association between stressful environment and visceral obesity (French et al., 2010).

The relationship between obesity and alcohol consumption is complex. Factors such as smoking, sedentary activity, physical inactivity, psychosocial factors, caffeine consumption and medication may further modify this association (French et al., 2010). A significant association between taking 2-4 bottles of alcohol per day and obesity was observed (Table 3). This is in line with a study that identified a higher BMI in heavier drinkers (Breslow and Smothers, 2005). Experimental evidence from several metabolic studies showed a suppression of lipid oxidation by alcohol and thus the enhancement of a positive fat accumulation (Suter and Tremblay, 2005).

The effects of ethnicity are also quiet significant and may pose an increased risk for obesity. Students originating from the Akan and Ga-Adangbe tribes were more likely to report higher prevalence of overweight and obesity respectively. The increase obesity among Ga-Adangbe students is consistent with Biritwum et al. (2005). The possible reason for high rate of obesity in Ga-Adangbe could be their 'kenkey' diet of the predominantly Ga people (Biritwum et al., 2005).

Training for health science education is stressful and the amount of material to be absorbed, social isolation, pressure of examination, and discrepancies be- tween expectation in exams results may play a key role as stressful condition leads to irregularity in diet, lack of exercise and addiction, each being considered independent factors leading to obesity (Gupta et al., 2009).

The present study also indicated that obesity and overweight were more likely to be associated with student from the College of Health Sciences and the College of Agric and Natural Sciences respectively. Previous works done among undergraduate health science students showed an increased prevalence of obesity and overweight (Gupta et al., 2009; Gopalakrishnan et al., 2012; Mogre et al., 2014). Overweight among the College of Agric and Natural sciences students is a new area emerging into the cascade of young adult obesity and thus early public health attention would help prevent future risk of obesity.

Logistic analysis showed that female students were at 12-folds increased odds of developing obesity/ overweight. This corresponds with finding of several studies authors (Oghagbon et al., 2009; Mogre et al., 2014; Onyechi and Okolo, 2017). Even though sample size and cross-sectional study design were limitation for this study and thus the findings can't conclusively represent general prevalence in young adults, the pattern of obesity and overweight are consistent with several authors.

\section{CONCLUSION}

Obesity and overweight is still increasing among young adults' population and female than male students are at increased risk. Being a fourth year student, reading health science related programmes and ethnicity of being Ga-Adangbe were more likely to be obese. Increase prevalence of underweight among first year students may have compounded the risk of obesity in fourth year student and thus public health especially institutional-based awareness on healthy lifestyle and nutrition are essential in early onset admission and students' orientation. Using other anthropometric measurements such as WC, WHR and WHtR in conjunction with BMI would be useful for better diagnosis of obesity condition. 


\section{Obesity prevalence among undergraduates}

Obirikorang et al.,

\section{COMPETING INTERESTS}

The authors declare that they have no competing interests.

\section{REFERENCES}

Akpinar E., Bashan I., Bozdemir N. and Saatci E. (2007) Which is the best anthropometric technique to identify obesity: body mass index, waist circumference or waist-hip ratio? Collegium antropologicum 31(2), 387-393.

Ashwell M. (2009) Obesity risk: importance of the waist-to-height ratio. Nursing Standard 23 (41), 49-54.

Bakr E., Ismail N. and Mahaba H. (2001) Impact of life style on the nutritional status of medical students at Ain Shams University. The Journal of the Egyptian Public Health Association 77 (1-2), 29-49.

Beatrice Adderley-Kelly PhD R. (2007) The prevalence of overweight and obesity among undergraduate health sciences students. $A B N F$ Journal 18(2), 46.

Bhurosy T. and Jeewon R. (2013) Pitfalls of using body mass index (BMI) in assessment of obesity risk. Current Research in Nutrition and Food Science 1(1), 71.

Biritwum R., Gyapong J. and Mensah G. (2005) The epidemiology of obesity in Ghana. Ghana Med J 39(3), 82-85.

Breslow R.A. and Smothers B.A. (2005) Drinking Patterns and Body Mass Index in Never Smokers National Health Interview Survey, 1997-2001. American journal of epidemiology 161(4), 368-376.

Chhabra P., Grover V., Aggarwal K. and Kanan A. (2006) Nutritional status and blood pressure of medical students in Delhi. Indian J Community Med 31(4), 248-251.

Croft J.B., Keenan N.L., Sheridan D.P., Wheeler F.C. and Speers M.A. (1995) Waist-to-hip ratio in a biracial population: measurement, implications, and cautions for using guidelines to define high risk for cardiovascular disease. Journal of the American Dietetic Association 95(1), 60-64.
French M.T., Norton E.C., Fang H. and Maclean J.C. (2010) Alcohol consumption and body weight. Health economics 19(7), 814-832.

Gopalakrishnan S., Ganeshkumar P., Prakash M. and Amalraj V. (2012) Prevalence of overweight/obesity among the medical students, Malaysia. The Medical Journal of Malaysia 67(4), 442-444.

Gupta S., Ray T.G. and Saha I. (2009) Overweight, obesity and influence of stress on body weight among undergraduate medical students. Indian Journal of Community Medicine 34 (3), 255.

Han T.S., Williams K., Sattar N., Hunt K.J., Lean M.E. and Haffner S.M. (2002) Analysis of obesity and hyperinsulinemia in the development of metabolic syndrome: San Antonio Heart Study. Obesity Research 10(9), 923931.

Kruger H.S., Puoane T., Senekal M. and van der Merwe M.-T. (2005) Obesity in South Africa: challenges for government and health professionals. Public bealth nutrition 8(05), 491-500.

McKeigue P., Shah B. and Marmot M. (1991) Relation of central obesity and insulin resistance with high diabetes prevalence and cardiovascular risk in South Asians. The Lancet 337(8738), 382-386.

Mogre V., Mwinlenaa P., Oladele J. and Amalba A. (2012) Impact of physical activity levels and diet on central obesity among civil servants in Tamale metropolis. Journal of Medical and Biomedical Sciences 1(2).

Mogre V., Nyaba R. and Aleyira S. (2014) Lifestyle risk factors of general and abdominal obesity in students of the school of medicine and health science of the University of Development Studies, Tamale, Ghana. ISRN obesity 2014.

Nakalema G. and Ssenyonga J. (2014) Academic stress: Its causes and results at a Ugandan University. African Journal of Teacher Education 3(3).

Oghagbon K., Odili V., Nwangwa E. and Pender K. (2009) Body mass index and blood pressure pattern of students in a Nigerian Uni- 


\section{Obesity prevalence among undergraduates}

Obirikorang et al.,

versity. International Journal of Health Research 2(2).

Onyechi U.A. and Okolo A.C. (2017) Prevalence of obesity among undergraduate students, living in halls of residence, University of Nigeria, Nsukka Campus, Enugu State. Animal Research International 5(3).

Reid I.R., Plank L.D. and Evans M.C. (1992) Fat mass is an important determinant of whole body bone density in premenopausal women but not in men. The Journal of Clinical Endocrinology \& Metabolism 75(3), 779-782.
Status W.P. (1995) The use and interpretation of anthropometry. Geneva CH: WHO 1995, technical report 854 .

Sturm R. (2002) The effects of obesity, smoking, and drinking on medical problems and costs. Health affairs 21(2), 245-253.

Suter P.M. and Tremblay A. (2005) Is alcohol consumption a risk factor for weight gain and obesity? Critical reviews in clinical laboratory sciences 42(3), 197-227.

WHO (2000) Obesity: preventing and managing the global epidemic: World Health Organization.
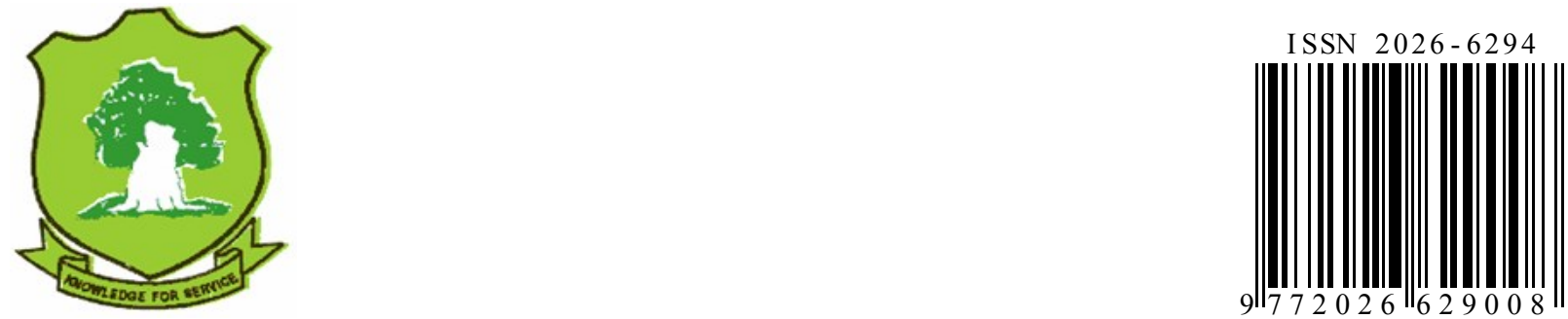